\title{
REDUÇÃO DE VITAMINA C EM SUCO DE CAJU (Anacardium occidentale L.) INDUSTRIALIZADO E CAJUÍNA
}

Eráclito Silva Lima, Elidiane Gomes Da Silva, José Machado Moita Neto e Graziella Ciaramella Moita*

Departamento de Química, Universidade Federal do Piauí, 64049-550 Teresina - PI, Brasil

Recebido em 19/6/06; aceito em 9/11/06; publicado na web em 5/6/07

\begin{abstract}
VITAMIN C DEGRADATION IN INDUSTRIALIZED CASHEW JUICE (ANACARDIUM OCCIDENTALE L.) AND IN CAJUINA. Vitamin $C$ degradation was evaluated in industrialized cashew juice of high pulp content and in cajuina by the method of Tillmans during eleven days of storage after the opening of the flask. For recently opened juices, vitamin $\mathrm{C}$ was found in the concentration range of 112 to $170 \mathrm{mg}$ for $100 \mathrm{~g}$ of juice. The degradation of vitamin $\mathrm{C}$ in industrialized cashew juices changes when different additives are used. All of the cajuinas presented a vitamin $\mathrm{C}$ content below that specified on the label.
\end{abstract}

Keywords: cashew juice; cajuina; vitamin C.

\section{INTRODUÇÃO}

O cajueiro pertence à família Anacardiaceae, havendo mais de 21 espécies relacionadas no gênero Anacardium, todas de ocorrência tipicamente tropical. O Anacardium occidentale L. é a única espécie cultivada e a de maior dispersão. É encontrada em diversos agroecossistemas brasileiros, embora se concentre principalmente nas zonas costeiras do Nordeste, como parte da vegetação de praias, dunas e nas formações de restinga ${ }^{1}$. Acredita-se que o cajueiro seja uma planta nativa do Brasil ou pelo menos do Norte da América do Sul, tendo como centro de origem mais provável o litoral nordeste do Brasil ${ }^{2}$.

A amêndoa da castanha do caju constitui-se no principal produto de utilização do cajueiro. O líquido da casca da castanha (LCC) e o pedúnculo, entretanto, também são derivados de grande importância no aproveitamento do cajueiro. O pedúnculo é consumido in natura ou industrializado sob a forma de sucos, sorvetes, doces diversos, licor, mel, geléias, cajuína, refrigerantes gaseificados, vinho e aguardente. $\mathrm{O}$ alto valor nutritivo do pedúnculo revela-se sob a forma de vitaminas e sais minerais, nele encontrando-se a vitamina $\mathrm{C}$ em níveis quase que cinco vezes maiores que na laranja, tendo ainda, entre outros a presença de cálcio, ferro e fósforo ${ }^{3,4}$.

O caju possui uma composição bastante complexa e, se por um lado, a presença de vitaminas, taninos, sais minerais, ácidos orgânicos e carboidratos o tornam um alimento importante, por outro, a oxidação dos elevados teores de ácido ascórbico (em média $230 \mathrm{mg} /$ $100 \mathrm{~g}$ ) e substâncias fenólicas (em média 0,35\%) é responsável por sua alta perecibilidade, provocando a formação de substâncias que causam o escurecimento do suco e a formação de aromas e sabores estranhos, exigindo cuidados especiais para estocagem, transporte, limpeza e processamento. Por esse motivo, a conservação do suco de caju integral só é possível mediante a adição de dióxido de enxofre em concentrações em torno de 500 a 600 ppm. Este valor está acima do recomendado pelas leis internacionais ${ }^{5}$.

O consumo de polpa do caju congelada tem aumentado, a exemplo de outras frutas. Um outro produto que está ganhando grande destaque é a cajuína, que é uma bebida elaborada a partir do suco de caju clarificado (não apresenta sólidos em suspensão) e esterilizado no interior da embalagem, apresentando cor amarelo-âmbar resultante da caramelização dos açúcares naturais do suco.

*e-mail: graziella@ufpi.br
Entretanto, o suco integral é o que possui maior importância econômica, sendo que o aproveitamento do pseudofruto em outros produtos ainda é mínimo em relação à quantidade de matéria-prima disponível. Estimativas apontam para $94 \%$ o volume desperdiçado do pedúnculo nos plantios estabelecidos na região Nordeste ${ }^{6}$.

A vitamina $\mathrm{C}$ é estável na forma seca e dissolve-se facilmente em água $(0,3 \mathrm{~g} / \mathrm{mL})$. Uma vez dissolvida, fica muito sensível ao oxigênio, luz e temperatura, estável em meio ácido e instável em meio alcalino. Sua oxidação pode ser acelerada na presença de cobre ou ferro ${ }^{7,8}$.

Devido ao uso difundido de vitamina $\mathrm{C}$, muitos métodos foram desenvolvidos para quantificá-la: titulométricos ${ }^{9-11}$, eletroquímicos ${ }^{9,12}$, luminescentes ${ }^{9}$, cinéticos ${ }^{9,13}$, fluorométricos ${ }^{9}$ e cromatográficos $^{9,14}$. Algumas técnicas consistem na adaptação de métodos volumétricos com detecção espectrofotométrica ${ }^{15}$, visando aumentar a velocidade de análise e baixar o consumo de reagentes.

O 2,6-diclorofenol indofenol (DCFI), conhecido como reativo de Tillmans, é o reagente mais popular para titulação direta de vitamina C. O DCFI é um indicador colorido que é reduzido pelo ácido ascórbico (AA).<smiles>O=C1C(Cl)=CC(=Nc2ccc(O)cc2)C=C1Cl</smiles>

DCFI<smiles>O=C1OC(C(O)CO)C(O)=C1O</smiles>

AA

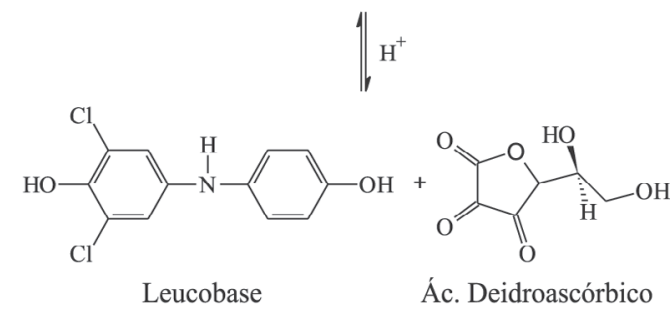

A aplicabilidade destes métodos é restrita a amostras de frutas cítricas e tabletes de multivitamina que não contêm minerais. Materiais coloridos dificultam a visualização do ponto final.

Maia, Monteiro e Guimarães ${ }^{5}$ mostraram que o teor de vitamina $\mathrm{C}$ em suco de caju integral apresenta perda de $65 \%$ no período de armazenamento de um ano, mesmo utilizando-se altos teores de $\mathrm{SO}_{2}$ como conservante. Segundo King e Pablo ${ }^{16}$, folhas verdes con- 
servadas a temperaturas de 10 e $21^{\circ} \mathrm{C}$ perdem 30 e $75 \%$ da vitamina $\mathrm{C}$, respectivamente, após 4 dias de estocagem. Pilon ${ }^{7}$ verificou que o teor de vitamina $\mathrm{C}$, em hortaliças minimamente processadas sob atmosfera modificada e refrigeração, não é afetado em um período de 21 dias. Em todos os trabalhos citados as análises foram realizadas pelo método de Tillmans. Nada se encontrou em literatura sobre a estabilidade do suco no período de armazenamento doméstico, após a abertura da embalagem.

Neste trabalho, determinou-se o teor de vitamina $\mathrm{C}$ pelo método de Tillmans em suco de caju industrializado com alto teor de polpa e cajuína, durante um período de 11 dias de armazenamento após a abertura do frasco, com o objetivo de verificar a degradação de vitamina $C$.

\section{PARTE EXPERIMENTAL}

\section{Amostras}

Analisaram-se 9 amostras de sucos industrializados de caju concentrado com alto teor de polpa (A a I) e de frutos de caju in natura $(\mathbf{J})$ coletados no Centro de Ciências Agrárias da Universidade Federal do Piauí. Avaliaram-se 9 amostras de cajuína (K a S) produzidas artesanalmente e uma cajuína produzida no laboratório (T). As amostras de produtos industrializados foram adquiridas no comércio local. Todas as amostras foram conservadas em geladeira, até o momento das análises.

\section{Obtenção do suco natural}

A extração do suco foi feita manualmente por esmagamento dos frutos, tomando-se o cuidado de obter um suco com o menor teor de polpa possível.

\section{Obtenção de cajuína em laboratório}

A cajuína foi obtida segundo técnica descrita por Paiva, Garrutti e Silva Neto ${ }^{17}$.

\section{Reagentes e soluções}

As soluções para determinação de ácido ascórbico foram preparadas como descritas pelo Instituto Adolfo Lutz ${ }^{11}$, para o método de Tillmans. Foi utilizado ácido metafosfórico (Merck), ácido acético (Vetec), 2-6-diclorofenol-indofenol sódico (Nuclear) e bicarbonato de sódio (Merck). Para a padronização da solução de Tillmans foi utilizado ácido ascórbico (Rosin). Todos os reagentes foram de grau analítico.

\section{Determinação de vitamina $\mathrm{C}$}

Pesou-se aproximadamente $1,0 \mathrm{~g}$ de suco e transferiu-se quantitativamente para um erlenmeyer de $125 \mathrm{~mL}$, utilizando-se cerca de $15 \mathrm{~mL}$ de água destilada. Adicionaram-se $15 \mathrm{~mL}$ da solução ácida (ácido metafosfórico/ácido acético). Efetuou-se a titulação com solução padrão de Tillmans até observar-se coloração rosa.

\section{Programação das análises}

A maioria dos sucos analisados indicava em seus rótulos que o mesmo deveria ser consumido em até 8 dias depois de aberto. Por isso, as determinações de vitamina $\mathrm{C}$ foram planejadas em intervalos de tempo distribuídos da seguinte forma: no dia da abertura da embalagem e após 3, 7 e 11 dias da abertura da embalagem. Mantiveram-se todas amostras sob refrigeração até o momento da aná- lise, para simular as condições reais às quais os sucos são mantidos até o momento do consumo.

\section{RESULTADOS E DISCUSSÃO}

\section{Avaliação da degradação de vitamina C em suco de caju industrializado}

A perda de vitamina $\mathrm{C}$ em suco de caju com alto teor de polpa foi apontada por Maia, Monteiro e Guimarães ${ }^{5}$ como sendo consequiência de vários fatores: a não injeção de nitrogênio na embalagem, a baixa concentração de dióxido de enxofre, a falta de cuidado na colheita e no transporte do caju etc.

Nos resultados para as análises realizadas nos sucos de caju concentrado com alto teor de polpa obtidos no mesmo dia da abertura da embalagem e após 3, 7 e 11 dias da abertura, há uma variação expressiva nos teores de vitamina $\mathrm{C}$ nas diferentes marcas de suco comercial. Concentrações na faixa de 112 a $170 \mathrm{mg}$ de vitamina C por $100 \mathrm{~g}$ da amostra foram encontradas para sucos recém-abertos.

Para todas as amostras comerciais, os teores de vitamina $\mathrm{C}$ foram superiores ao limite mínimo estabelecido para este tipo de suco, que é de $80 \mathrm{mg} / 100 \mathrm{~g}$ de amostra ${ }^{18}$, mesmo após 7 dias de abertura das embalagens. Após 11 dias, apenas duas amostras comerciais (G e I) tiveram teores de vitamina $\mathrm{C}$ inferiores ao mínimo permitido. Portanto, a informação do rótulo de alguns sucos que deveriam ser consumidos em até 8 dias após a abertura da embalagem, em relação à conservação do teor de vitamina $\mathrm{C}$, é adequada.

O suco identificado pela letra $\mathbf{J}$ destaca-se dos demais pelo alto teor de vitamina C (cerca de $244 \mathrm{mg} / 100 \mathrm{~g}$ ). Ele foi obtido a partir do esmagamento manual da fruta fresca e imediatamente analisado. Esse processo minimiza a aeração e, conseqüentemente, possibilita melhor preservação da vitamina $\mathrm{C}$ do que no produto industrializado. Como esta amostra não continha conservante, após 11 dias houve uma variação no teor de vitamina $\mathrm{C}$ mais acentuado que o observado para os sucos industrializados.

Pelo teste t pareado, observa-se que, com $95 \%$ de probabilidade, não há diferença significativa entre os teores de vitamina $\mathrm{C}$ na amostra desde o momento da abertura da embalagem até 3 dias depois. Isto ocorre por conta da grande variação na diferença dos pares introduzida pela amostra $\mathbf{J}$ no conjunto de dados. Pode-se observar que, com o passar do tempo, o suco $\mathbf{J}$ foi o que apresentou maior redução de vitamina, 23,2\%, após 3 dias. A este suco não foi adicionado nenhum aditivo para preservação da vitamina $\mathrm{C}$.

$\mathrm{O}$ gráfico do teor de vitamina $\mathrm{C}$ no momento da abertura da

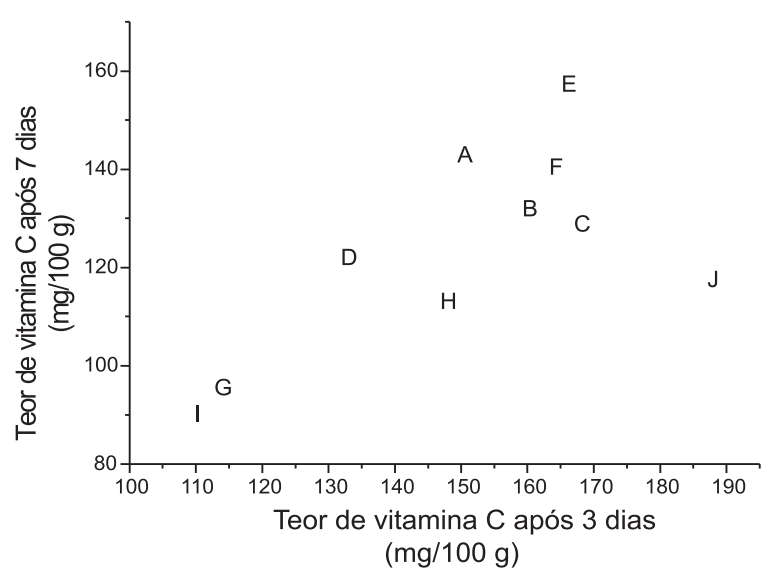

Figura 1. Relação entre teor de Vitamina C ( $\mathrm{mg} / 100 \mathrm{~g})$ em suco de caju concentrado com alto teor de polpa obtido no dia da abertura da embalagem da amostra e após três dias de armazenamento, mantidos sob refrigeração 
embalagem versus o teor de vitamina $\mathrm{C}$ após 3 dias está mostrado na Figura 1. Percebe-se que há uma correlação linear entre os teores de vitamina $\mathrm{C}$ no dia da abertura da amostra e 3 dias após a abertura; no entanto, nota-se que a amostra $\mathbf{J}$ (suco natural) é claramente um ponto diferente do resto do conjunto ("outlier"), tanto pelo seu alto valor de vitamina $\mathrm{C}$ inicial como pela maior rapidez que a vitamina C é oxidada após 3 dias. Devido a isto, o teste t pareado foi refeito para o conjunto excluindo a amostra $\mathbf{J}$ e o resultado indicou uma diferença significativa de vitamina $\mathrm{C}$ entre o momento da abertura dos sucos e após 3 dias de aberto. A redução de vitamina $\mathrm{C}$ foi, em média, de 3,4 mg/100 g durante o período de 3 dias.

Após 7 dias da abertura da embalagem, período próximo ao prazo limite estabelecido pelas empresas para consumo do produto ( 8 dias), verificou-se que, entre os sucos industrializados, o identificado pela letra $\mathbf{C}$ apresentou a maior redução de vitamina $\mathbf{C}$ $(24,2 \%)$ comparando-se com a primeira análise. Para os demais sucos, a perda de vitamina $\mathrm{C}$ ficou próxima de $20,0 \%$.

A amostra $\mathbf{J}$ continua se destacando como uma amostra diferente das outras ("outlier") quando se comparam os teores de vitamina $\mathrm{C}$ com 7 dias de abertura da embalagem do suco e os teores encontrados para 3 dias. Além disso, observa-se que a relação linear entre estes dois tempos de análise está restrita às amostras $\mathbf{I}, \mathbf{G}$, D, A e E. Este grupo está sendo oxidado mais lentamente que as demais amostras, apresentando um decréscimo médio de vitamina $\mathrm{C}$ de $12,3 \mathrm{mg} / 100 \mathrm{~g}$, enquanto que o conjunto tem um decréscimo médio de 25,4 mg/100 g.

Comparando-se as quantidades de vitamina C 3 dias após a abertura da embalagem da amostra e 7 dias depois através do teste t pareado $(\mathrm{p}=0,05)$, verifica-se que há uma diferença estatística, mesmo quando se coloca a amostra $\mathbf{J}$ no conjunto de dados.

Para um período de 11 dias após a abertura da amostra, os valores obtidos mostram que a perda de vitamina $\mathrm{C}$ para os sucos industrializados foi em média de $32,8 \%$, sendo que para o suco natural a oxidação chega a $66,6 \%$. Essa perda significativa de vitamina $\mathrm{C}$, com relação ao sétimo dia é confirmada através do teste $\mathrm{t}$ pareado $(\mathrm{p}=0,05)$. As amostras $\mathbf{G}$ e I tiveram seus teores de vitamina $\mathrm{C}$ menores que o recomendado, ficando a amostra $\mathbf{J}$ ligeiramente superior à faixa.

A relação linear entre as amostras I, G, D, A e E ficou preservada, quando comparados os teores de vitamina $\mathrm{C}$ com 11 dias de abertura da embalagem do suco e os encontrados para 7 dias. Este grupo apresentou um decréscimo médio de $16,5 \mathrm{mg} / 100 \mathrm{~g}$ de vitamina $\mathrm{C}$, enquanto que o conjunto teve um decréscimo de $21,1 \mathrm{mg} / 100 \mathrm{~g}$.

Analisando-se o grupo de amostras que manteve um comportamento linear durante os 11 dias, observa-se que a taxa de oxidação de vitamina $\mathrm{C}$ por dia para $100 \mathrm{~g}$ de amostra em cada intervalo foi de 1,$13 ; 3,08$ e $4,13 \mathrm{mg}$. Isto significa que a degradação de vitamina $C$ se acelerou com o tempo. A taxa de oxidação de vitamina $\mathrm{C}$ por dia para $100 \mathrm{~g}$ da amostra $\mathbf{J}$ em cada intervalo foi de 18,91; 17,43 e 8,99 mg, mostrando uma constância na perda de vitamina $\mathrm{C}$ nos primeiros 7 dias e uma desaceleração nos últimos 4 dias.

A taxa de oxidação de vitamina $\mathrm{C}$ do suco natural permaneceu superior ao suco de caju industrializado, indicando que os conservantes adicionados ao produto industrializado ainda estavam atuando no suco no período entre o $7^{\circ}$ e o $11^{\circ}$ dias após a abertura da embalagem.

\section{Avaliação da degradação de vitamina $\mathrm{C}$ em suco de caju clarificado (cajuína)}

Das 9 amostras de cajuína analisadas nenhuma trazia informação acerca do período de consumo após a abertura da embalagem; então se decidiu por fazer as determinações de ácido ascórbico nas diferentes amostras de cajuína seguindo o mesmo procedimento descrito para o suco de caju com alto teor de polpa. Todas as cajuínas analisadas são de fabricação artesanal e obtidas no comércio local; a data de fabricação das diferentes marcas diferia em no máximo 43 dias. Analisou-se também uma cajuína produzida no laboratório a partir da clarificação e tratamento térmico $\left(100{ }^{\circ} \mathrm{C}\right.$ por 50 min) do suco natural obtido pelo esmagamento de frutas frescas.

Exceto para as amostras $\mathbf{L}$ e $\mathbf{T}$, os resultados para as determinações de vitamina $\mathrm{C}$ em cajuína no mesmo dia em que a embalagem foi aberta, 3, 7 e 11 dias após a abertura da embalagem estão abaixo do limite mínimo estabelecido para este tipo de suco, que é de $60 \mathrm{mg} / 100 \mathrm{~g}$ de amostra ${ }^{18}$. Em conversa com produtores locais sobre a qualidade das cajuínas, verificou-se que há preocupação em adequar o processo de produção para melhorar a preservação da vitamina $\mathrm{C}$, contudo eles não possuem meios para investir no controle de qualidade do processo.

A cajuína $\mathbf{P}$ destaca-se por apresentar um teor de vitamina $50 \%$ menor que a média das demais. Como esta amostra se apresentava visualmente bem mais escura que as outras cajuínas, o seu menor teor de vitamina $\mathrm{C}$ deve estar relacionado ao maior tempo de cozimento, pois a vitamina $\mathrm{C}$ é sensível ao calor. A cajuína $\mathbf{T}$ foi obtida no laboratório no dia anterior à análise, seguindo método descrito por produtores locais, e apresentou um teor de vitamina $\mathrm{C}$ $60 \%$ maior que as demais. Portanto, há um descontrole no processo artesanal de fabricação de cajuína que precisa ser sanado.

Através do teste t pareado $(\mathrm{p}=0,05)$, observa-se que há diferença estatística entre os teores de vitamina $\mathrm{C}$ nas amostras desde o momento da abertura da embalagem até 3 dias depois, isso mostra que está ocorrendo oxidação do ácido ascórbico. O decréscimo médio de vitamina $\mathrm{C}$ neste período foi de $3,7 \mathrm{mg} / 100 \mathrm{~g}$.

$\mathrm{A}$ perda média de vitamina $\mathrm{C}$ aos três dias em relação à abertura da embalagem de cajuína foi de $6 \%$. A amostra $\mathbf{T}$ sofreu a maior perda relativa $(12,8 \%)$ de vitamina $\mathrm{C}$. As variações mais acentuadas entre as cajuínas comerciais foram verificadas nas marcas $\mathbf{L}$ e $\mathbf{N}$, que tiveram uma redução de aproximadamente $7 \%$.

Existe uma relação linear entre os teores de vitamina $\mathrm{C}$ dos tempos zero e 3 dias $(r=0,998)$, indicando que as diversas marcas de cajuína têm comportamento semelhante em relação à oxidação da vitamina $\mathrm{C}$.

Para as análises realizadas em cajuína sete dias após a abertura da amostra, verifica-se que entre as cajuínas comerciais a amostra $\mathbf{L}$ apresentou a menor conservação de vitamina $\mathbf{C}$, com redução de $19,5 \%$, e a amostra $\mathbf{K}$ destaca-se com boa estabilidade, perdendo apenas $6,8 \%$ do teor de vitamina quando comparada com a primeira análise. Para as demais cajuínas a perda de vitamina $\mathrm{C}$ ficou próxima de $13,0 \%$. A relação linear entre os teores de vitamina $\mathrm{C}$ dos tempos 3 e 7 dias $(r=0,992)$ indica o mesmo padrão de oxidação da vitamina $\mathrm{C}$ neste segundo período.

Os valores obtidos para os teores de vitamina $\mathrm{C}$ nas cajuínas, 11 dias após a abertura da embalagem apresentam uma redução bem maior em relação à análise anterior. Verifica-se que, mesmo não possuindo conservantes, as cajuínas se mostraram mais estáveis que os sucos com alto teor de polpa no período de 11 dias de armazenagem após a abertura da embalagem, com redução média no teor de vitamina $\mathrm{C}$ de 25,4 e $34,5 \%$, respectivamente.

Há uma relação linear $(r=0,985)$ entre teores de vitamina $C$ após 7 e 11 dias de abertura da embalagem, indicando a persistência do padrão de oxidação de vitamina $\mathrm{C}$. Apenas a cajuína de laboratório manteve-se com teor de vitamina $\mathrm{C}$ acima do limite mínimo com 7 dias de abertura da embalagem.

O comportamento cinético da reação de oxidação de vitamina C, obtida através do método de Tillmans, para as marcas de cajuína T, P e L está mostrado na Figura 2. A variação do teor de vitamina 


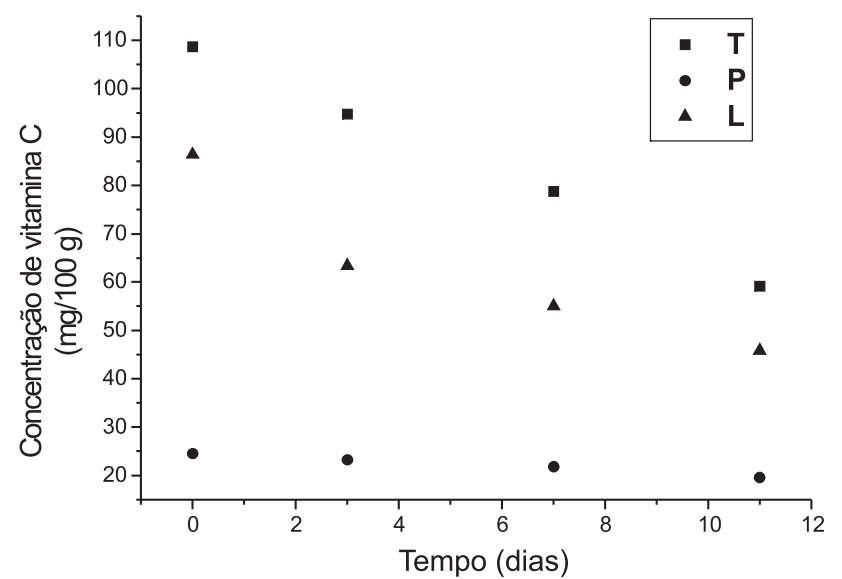

Figura 2. Cinética de oxidação de vitamina C em cajuína durante o armazenamento, sob refrigeração

C nas amostras de cajuínas analisadas, ao longo de 11 dias de armazenamento após a abertura da embalagem, não evidencia etapas distintas no processo de oxidação do ácido ascórbico, como ocorre com os sucos com alto teor de sólidos.

Também foram realizadas análises para determinar as perdas de vitamina $\mathrm{C}$ durante o processamento em laboratório (clarificação e tratamento térmico) do suco para obtenção da cajuína. Verificou-se um decréscimo de 14,8\% no teor de vitamina C durante a etapa de clarificação do suco e uma perda de 55,4\% em relação ao suco integral logo após o processamento em laboratório, para obter a cajuína. Na primeira fase a perda de vitamina é devido à aeração que ocorre durante a agitação e a filtração e, depois, a oxidação é acentuada com o aquecimento, que ocorreu em sistema aberto.

\section{CONCLUSÃO}

Comparando-se os resultados obtidos para os teores de vitamina $\mathrm{C}$ nas diversas amostras de suco de caju com alto teor de polpa, observou-se que há uma grande diferença na quantidade de vitamina $\mathrm{C}$ inicial entre as várias marcas. Além disso, o padrão diferente de perda de vitamina $\mathrm{C}$ indica diferentes teores de conservante utilizado em cada um dos produtos industrializados.

Nas amostras de cajuína verificou-se que o teor de vitamina C encontra-se abaixo do limite estabelecido, necessitando melhor controle de qualidade no processamento das mesmas. Uma cajuína processada com os cuidados de laboratório mantém o teor de vitamina $\mathrm{C}$ acima do mínimo estabelecido por tempo superior a 7 dias após sua preparação.

\section{MATERIAL SUPLEMENTAR}

Os teores de vitamina $\mathrm{C}$, determinados no mesmo dia da abertura da embalagem e após 3, 7 e 11 dias da abertura, e suas correlações entre estes períodos, para os sucos de caju concentrado e cajuínas, estão disponíveis em http://quimicanova.sbq.org.br, na forma de arquivo PDF, com acesso livre e gratuito.

\section{REFERÊNCIAS}

1. Lima, V. P. M. S.; A cultura do cajueiro no Nordeste do Brasil, Banco do Nordeste do Brasil-ETENE: Fortaleza, 1988.

2. http://www.cpatsa.embrapa.br/catalogo/livrorg/cajurecursosgeneticos.pdf, acessada em Junho 2006.

3. Cavalcanti, J. J. V. Em O cajueiro: exploração, perspectivas e potencialidades no âmbito da Mata Atlântica; Simões, L. L.; Lino, C. F., orgs..; Senac: São Paulo, 2002, p. 55.

4. Araújo, J. P. P.; Silva, V. V.; Cajucultura: modernas técnicas de produção, Embrapa-CNPAT: Fortaleza, 1995.

5. Maia, G. A.; Monteiro, J. C. S.; Guimarães, A. C. L.; Ciênc. Tecnol. Aliment. 2001, 21, 43.

6. Embrapa; Relatório Técnico Anual do Centro Nacional de Pesquisa de Caju 1991-1992, Embrapa-CNPCa: Fortaleza, 1993.

7. Pilon, L.; Dissertação de Mestrado, Universidade de São Paulo, Brasil, 2003.

8. Almeida. G. S. C.; Dissertação de Mestrado, Universidade de São Paulo, Brasil, 2003.

9. Arya, S. P.; Mahajan, M.; Jain, P.; Anal. Chim. Acta 2000, 417, 1.

10. Suntornsuk, L.; Gritsanapun, W.; Nilkamhank, S.; Paochom, A.; J. Pharm. Biomed. Anal. 2002, 28, 849; East, G. A.; Nascimento, E. C.; J. Chem. Educ. 2002, 79, 100; Kumar, K. G.; Indrasenan, P.; Talanta 1990, 37, 269.

11. Instituto Adolfo Lutz; Normas Analíticas do Instituto Adolfo Lutz. Métodos químicos e físicos para análise de alimentos, 3a ed., São Paulo, 1985, vol. 1, p. 393.

12. Kolar, M.; Dobcnik, D.; Radic, N.; Pharmazie 2000, 55, 913; Abulkibash, A. M. S.; Koken, M. E.; Khaled, M. M.; Sultan, S. M.; Talanta 2000, 52 , 1139; Pournaghiazar, M. H.; Ojani, R.; Talanta 1997, 44, 297.

13. Sultan, S. M.; Desai, N. I.; Talanta 1998, 45, 1061; Sultan, S. M.; Bishop, E.; J. Pharm. Biomed. Anal. 1990, 8, 345.

14. Koshiishi, I.; Mamura, Y.; Imanari, T.; J. Chromatogr., A 1998, 806, 340.

15. Kleszczewski, T.; Kleszczewska, E.; J. Pharm. Biomed. Anal. 2002, 29, 755; Arya, S. P.; Mahajan, M.; Jain, P.; Anal. Chim. Acta. 2001, 427, 245; Elbashier, E. E.; Greenway, G. M.; J. Micronutrient Analysis 1999, 311; Sarkar, M.; Sarkar, A. R.; Analusis 1994, 155.

16. King, J. R.; Pablo, S.; Revista Chilena de Nutricion 1987, 5, 143 apud ref. 7 .

17. Paiva, F. F. A.; Garrutti, D. S.; Silva Neto, R. M.; Aproveitamento industrial do caju, Embrapa Agroindústria Tropical/SEBRAE: Fortaleza, 2000.

18. http://oc4j.agricultura.gov.br/agrolegis/do/consultaLei?op=view Textual\&codigo=7777, acessada em Junho 2006. 


\section{REDUÇÃO DE VITAMINA C EM SUCO DE CAJU (Anacardium occidentale L.) INDUSTRIALIZADO E CAJUÍNA}

Eráclito Silva Lima, Elidiane Gomes da Silva, José Machado Moita Neto e Graziella Ciaramella Moita Departamento de Química, Universidade Federal do Piauí, 64049-550, Teresina - PI, Brasil

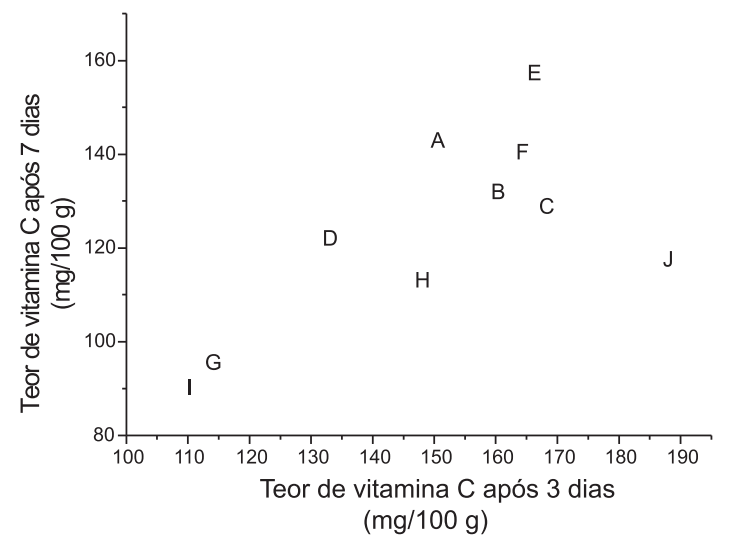

Figura 1S. Relação entre teor de vitamina $\mathrm{C}(\mathrm{mg} / 100 \mathrm{~g})$ em suco de caju concentrado com alto teor de polpa obtido após 7 dias da abertura da embalagem da amostra e após 3 dias de armazenamento, mantidos sob refrigeração

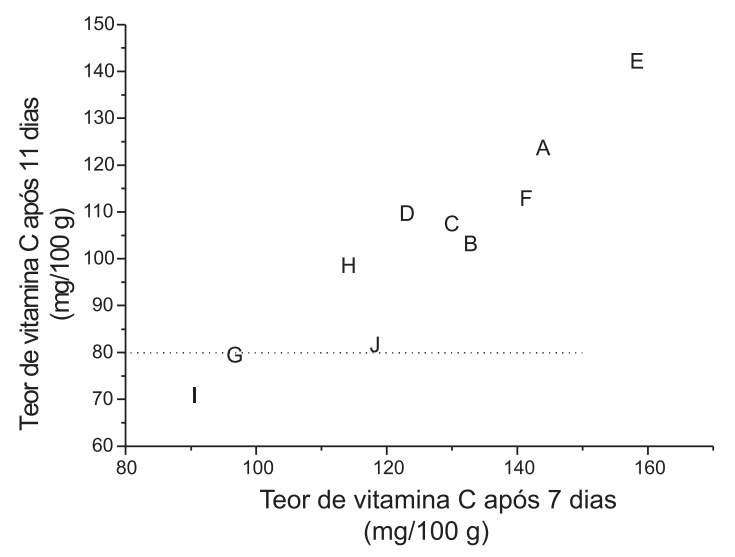

Figura 2S. Relação entre teor de vitamina $C(\mathrm{mg} / 100 \mathrm{~g})$ em suco de caju concentrado com alto teor de polpa obtido após 11 dias da abertura da embalagem da amostra e após 7 dias de armazenamento, mantidos sob refrigeração

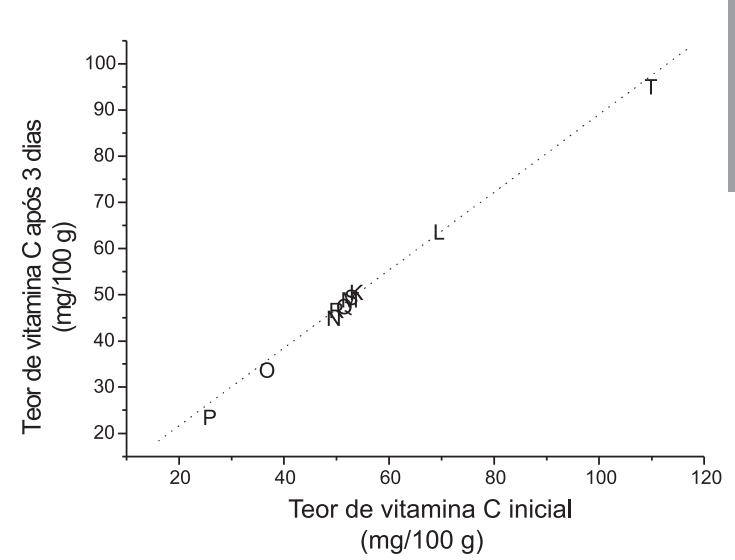

Figura 3S. Relação entre teor de vitamina C ( $\mathrm{mg} / 100 \mathrm{~g})$ em cajuínas no dia da abertura da embalagem da amostra e após 3 dias de armazenamento, mantidos sob refrigeração

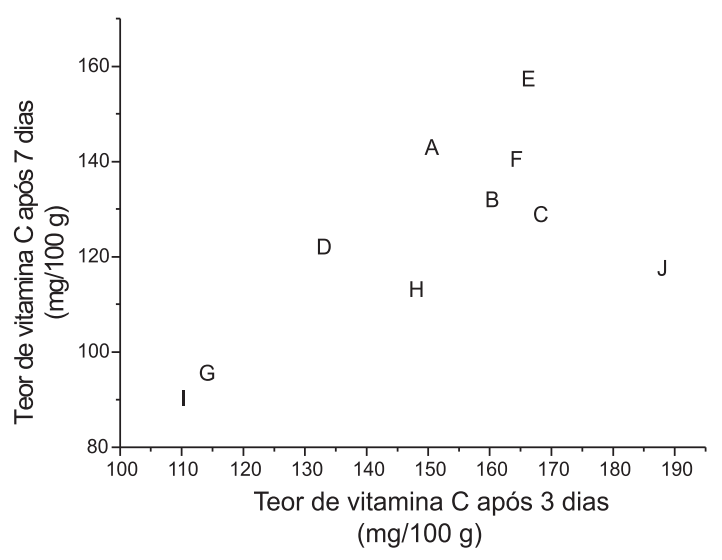

Figura 4S. Relação entre teor de vitamina C (mg/100 g) em cajuínas após 11 dias da abertura da embalagem da amostra e após 7 dias de armazenamento, mantidos sob refrigeração 
Tabela 1S. Teor de vitamina $\mathrm{C}(\mathrm{n}=3)$ em suco de caju com alto teor de polpa e respectivo desvio padrão relativo (Sr), no dia da abertura da embalagem da amostra e após 3, 7 e 11 dias de armazenamento, mantidos sob refrigeração

\begin{tabular}{|c|c|c|c|c|c|c|c|c|}
\hline \multirow{3}{*}{ Amostra } & \multicolumn{8}{|c|}{ Teor de vitamina $\mathrm{C}$} \\
\hline & \multicolumn{2}{|c|}{$0 \mathrm{dia}$} & \multicolumn{2}{|c|}{3 dias } & \multicolumn{2}{|c|}{7 dias } & \multicolumn{2}{|c|}{11 dias } \\
\hline & $\mathrm{mg} / 100 \mathrm{~g}$ & $\mathrm{Sr}(\%)$ & $\mathrm{mg} / 100 \mathrm{~g}$ & $\mathrm{Sr}(\%)$ & $\mathrm{mg} / 100 \mathrm{~g}$ & $\mathrm{Sr}(\%)$ & $\mathrm{mg} / 100 \mathrm{~g}$ & $\mathrm{Sr}(\%)$ \\
\hline $\mathrm{A}$ & 152,17 & 0,86 & 149,42 & 0,37 & 142,83 & 0,78 & 123,54 & 0,93 \\
\hline B & 162,21 & 0,21 & 159,20 & 0,58 & 131,76 & 0,71 & 102,98 & 0,54 \\
\hline $\mathrm{C}$ & 169,92 & 0,28 & 166,98 & 0,51 & 128,74 & 0,55 & 107,30 & 0,09 \\
\hline $\mathrm{D}$ & 137,58 & 0,13 & 131,86 & 0,98 & 121,93 & 0,78 & 109,46 & 0,51 \\
\hline $\mathrm{E}$ & 166,27 & 0,42 & 165,11 & 0,17 & 157,19 & 0,27 & 141,97 & 0,82 \\
\hline $\mathrm{F}$ & 168,89 & 0,28 & 163,23 & 0,41 & 140,32 & 0,41 & 112,67 & 0,63 \\
\hline $\mathrm{G}$ & 118,04 & 0,21 & 112,76 & 0,95 & 95,41 & 1,31 & 79,25 & 1,12 \\
\hline $\mathrm{H}$ & 148,51 & 0,24 & 146,81 & 0,43 & 112,96 & 0,66 & 98,37 & 0,48 \\
\hline I & 112,35 & 0,12 & 109,76 & 0,54 & 90,07 & 0,56 & 70,66 & 0,54 \\
\hline $\mathrm{J}$ & 243,87 & 0,28 & 187,13 & 0,38 & 117,39 & 0,83 & 81,44 & 0,68 \\
\hline
\end{tabular}

Tabela 2S. Teor de vitamina $\mathrm{C}(\mathrm{n}=3)$ em cajuína e respectivo desvio padrão relativo $(\mathrm{Sr})$, no dia da abertura da embalagem da amostra e 3, 7 e 11 dias de armazenamento, mantidos sob refrigeração

\begin{tabular}{|c|c|c|c|c|c|c|c|c|}
\hline \multirow{3}{*}{ Amostra } & \multicolumn{8}{|c|}{ Teor de vitamina $\mathrm{C}$} \\
\hline & \multicolumn{2}{|c|}{0 dia } & \multicolumn{2}{|c|}{3 dias } & \multicolumn{2}{|c|}{7 dias } & \multicolumn{2}{|c|}{11 dias } \\
\hline & $\mathrm{mg} / 100 \mathrm{~g}$ & $\mathrm{Sr}(\%)$ & $\mathrm{mg} / 100 \mathrm{~g}$ & $\mathrm{Sr}(\%)$ & $\mathrm{mg} / 100 \mathrm{~g}$ & $\operatorname{Sr}(\%)$ & $\mathrm{mg} / 100 \mathrm{~g}$ & $\mathrm{Sr}(\%)$ \\
\hline $\mathrm{K}$ & 52,41 & 0,50 & 50,27 & 0,26 & 48,80 & 0,16 & 43,27 & 0,42 \\
\hline $\mathrm{L}$ & 68,36 & 0,37 & 63,34 & 0,21 & 55,02 & 0,18 & 45,77 & 0,46 \\
\hline M & 50,78 & 0,49 & 48,68 & 0,80 & 44,32 & 0,95 & 39,29 & 0,71 \\
\hline $\mathrm{N}$ & 47,98 & 1,42 & 44,63 & 0,92 & 39,90 & 0,38 & 35,27 & 0,17 \\
\hline $\mathrm{O}$ & 35,14 & 0,71 & 33,40 & 0,66 & 29,37 & 0,72 & 26,04 & 0,46 \\
\hline $\mathrm{P}$ & 24,51 & 1,02 & 23,19 & 1,60 & 21,81 & 1,42 & 19,58 & 0,97 \\
\hline Q & 49,9 & 0,52 & 47,19 & 0,17 & 43,42 & 0,21 & 38,61 & 0,44 \\
\hline $\mathrm{R}$ & 48,47 & 0,62 & 46,38 & 0,54 & 44,07 & 0,57 & 39,07 & 0,82 \\
\hline$S$ & 51,49 & 0,12 & 49,17 & 1,38 & 45,53 & 0,55 & 40,37 & 0,79 \\
\hline $\mathrm{T}$ & 108,66 & 0,23 & 94,74 & 0,19 & 78,75 & 0,25 & 59,16 & 1,01 \\
\hline
\end{tabular}

Tabela 3S. Teor de vitamina $\mathrm{C}(\mathrm{n}=3)$ em suco de caju e respectivo desvio padrão relativo $(\mathrm{Sr})$, em uma amostra antes e depois de ter sido processada (no laboratório) para obtenção de cajuína

\begin{tabular}{lcc}
\hline Amostra & Teor de vitamina C (mg/100 g) & Sr $(\%)$ \\
\hline Suco de caju in natura & 243,87 & 1,12 \\
Suco de caju clarificado sem cozimento & 207,56 & 0,58 \\
Suco de caju clarificado após cozimento* & 108,66 & 0,23 \\
\hline
\end{tabular}

*Aquecimento por $50 \min$ a $100^{\circ} \mathrm{C}$ 